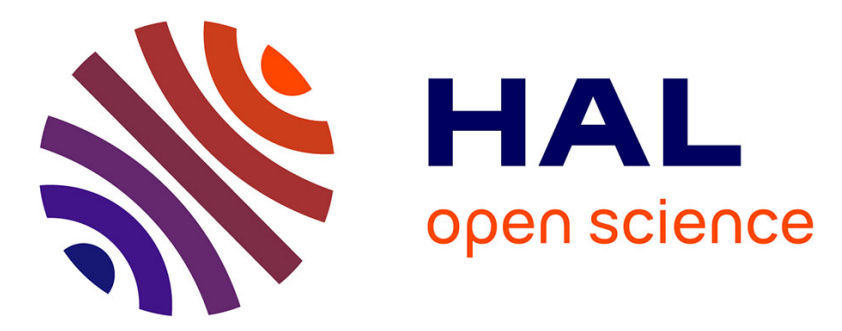

\title{
Risk factors for resistance in urinary tract infections in women in general practice: A cross-sectional survey
} Louise Rossignol, Sylvie Maugat, Alexandre Blake, Sophie Vaux, Beate Heym, Yann Le Strat, Solen Kernéis, Thierry Blanchon, Bruno Coignard, Thomas Hanslik

\section{To cite this version:}

Louise Rossignol, Sylvie Maugat, Alexandre Blake, Sophie Vaux, Beate Heym, et al.. Risk factors for resistance in urinary tract infections in women in general practice: A cross-sectional survey. Journal of Infection, 2015, 71 (3), pp.302-311. 10.1016/j.jinf.2015.05.012 . hal-01170431

\section{HAL Id: hal-01170431 \\ https://hal.sorbonne-universite.fr/hal-01170431}

Submitted on 6 Jul 2015

HAL is a multi-disciplinary open access archive for the deposit and dissemination of scientific research documents, whether they are published or not. The documents may come from teaching and research institutions in France or abroad, or from public or private research centers.
L'archive ouverte pluridisciplinaire HAL, est destinée au dépôt et à la diffusion de documents scientifiques de niveau recherche, publiés ou non, émanant des établissements d'enseignement et de recherche français ou étrangers, des laboratoires publics ou privés. 
survey

Running title: Risk factors for resistance in urinary tract infections

Louise Rossignol $^{\mathrm{a}, \mathrm{b}, \mathrm{c}}$, Sylvie Maugat ${ }^{\mathrm{d}}$, Alexandre Blake ${ }^{\mathrm{d}}$, Sophie Vaux ${ }^{\mathrm{d}}$, Beate Heym ${ }^{\mathrm{e}, \mathrm{f}}$, Yann Le Strat ${ }^{d}$, Solen Kernéis $^{c}$, Thierry Blanchon ${ }^{b, c}$, Bruno Coignard $^{d}$, Thomas Hanslik ${ }^{c, e, f}$

\section{Affiliations:}

åDépartement de Médecine Générale, UPMC Univ Paris 06, 27 rue Chaligny, 75012 Paris, France;

bSorbonne Universités, UPMC Univ Paris 06, UMR_S 1136, Institut Pierre Louis d'Epidémiologie et de Santé

Publique, 56, boulevard Vincent Auriol - CS 81393 - 75646 Paris, France;

'INSERM, UMR_S 1136, Institut Pierre Louis d'Epidémiologie et de Santé Publique, 56, boulevard Vincent Auriol - CS 81393 - 75646 Paris, France;

${ }^{d}$ Institut de Veille Sanitaire, 12, rue du Val d'Osne 94415 Saint-Maurice cedex, France

${ }^{\mathrm{e} H o p i t a l}$ universitaire Ambroise Paré AP-HP, 9, avenue Charles-de-Gaulle - 92100 Boulogne-Billancourt, France;

'Université Versailles-Saint-Quentin-en-Yvelines, 55 Avenue de Paris, 78000 Versailles, France.

${ }^{\S}$ Corresponding author

Email addresses:

LR: louise.rossignol@upmc.fr

SM: s.maugat@invs.sante.fr

AB: blake.alexandre@hotmail.fr

SV: s.vaux@invs.sante.fr

BH: beate.heym@apr.aphp.fr

YLS: y.lestrat@invs.sante.fr

TB: thierry.blanchon@upmc.fr

BC: $\underline{\text { b.coignard@invs.sante.fr }}$

TH: thomas.hanslik@apr.aphp.fr 


\section{Highlights}

- Individual factors associated with drug-resistant UTIs in general practice are scarce

- Only two factors were associated with drug-resistant UTIs:

- Penicillin use in the previous three months

- Exposure to a person returning from an area with a high risk of drug resistance

- A protective role of raw meat consumption has been found and should be explored

\section{Summary}

\section{Objectives}

In 2012 and 2013, a cross-sectional survey was conducted in women visiting a general practitioner for a urinary tract infection (UTI) to i) describe the patterns of antibiotic resistance of Enterobacteriaceae involved in communityacquired UTIs and ii) identify the factors associated with UTIs due to a multi-drug-resistant Enterobacteriaceae (MDREB).

\section{Methods}

Urine analyses were performed systematically for all adult women presenting with signs of UTI. Characteristics of women with UTI due to MDREB were compared to those with UTI due to non-MDREB. Weighted logistic regressions were performed to adjust for the sampling design of the survey.

\section{Results}

Significant factors associated with MDREB included the use of penicillin by the patient in the last three months $(\mathrm{OR}=$ $3.1 ;[1.2-8.0])$; having provided accommodation in the previous 12 months to a resident from a country at high risk for drug resistance $(O R=4.0 ;[1.2-15.1])$; and the consumption of raw meat within the previous three months $(O R=0.3$; $[0.1-0.9])$.

\section{Conclusions}

In the community, antibiotic use and exposure to a person returning from an area with a high risk of drug resistance are associated with UTIs due to MDREB. The potentially protective role of raw meat consumption warrants further study.

Key words: urinary tract infection, epidemiology, antibiotic resistance, risk factors, general population, general practitioner 
Urinary tract infections (UTIs) are among the most common bacterial infections. In the United States, one-third of all women have had at least one physician-diagnosed presumed UTI by the age of 26 years (1). UTIs are typically caused by Enterobacteriaceae, such as Escherichia coli (E. coli), which are involved in $70-80 \%$ of cases (2).

The epidemiology of antimicrobial resistance varies among countries, particularly due to the impact of antibiotic prescriptions (3-5). In France, in 2009, the resistance rates of E. coli reached $55 \%$ for amoxicillin, $18 \%$ for fluoroquinolone, $8 \%$ for aminoglycoside and $10 \%$ for third-generation cephalosporin in healthcare-related infections (6). In 2011, the incidence of patients with at least one diagnostic sample testing positive for extended-spectrum $\beta$ lactamase Enterobacteriaceae (ESBLE) was 0.46 per 1000 days of hospitalization in French acute care hospitals (7). Data are scant for community-onset UTIs, as urine analysis is not mandatory in the treatment of uncomplicated cystitis. Thus, in previous epidemiological studies, urine cultures were not obtained for all women presenting with symptoms of UTI, but rather for women with complicated UTIs or UTIs seen in healthcare settings.

The empirical therapy of UTIs should be guided by knowledge of antimicrobial resistance and by identifying risk factors for resistance (8). Known risk factors include previous hospitalization, previous antibiotic use, urinary catheterization and recurrent UTIs $(9,10)$. Other risk factors have been suspected, although they are less clearly established, such as international travel, living with pets, eating fish or raw meat, and swimming (11-13). Almost all of these risk factors have been identified in hospitalized patients. However, most UTIs occur in the community and are frequently treated in the absence of urine analysis. Data on the epidemiology of drug resistance in this setting are scant. Therefore, to identify factors associated with antimicrobial resistance in UTIs caused by Enterobacteriaceae in the French community, we conducted a cross-sectional survey in women visiting a general practitioner (GP) for a suspected UTI. Urine analysis was performed for all included individuals. 


\section{Design and study population}

The study population was derived from a national cross-sectional prospective survey, titled Drug resistant Urinary Tract Infection (Druti), that was conducted in France in 2012 and 2013 by general practitioners (GPs) of the Sentinelles network (14) to estimate the annual incidence of UTIs due to antibiotic-resistant Enterobacteriaceae in women visiting a GP for a suspected UTI (the results were pending at the time that this manuscript was written). In brief, a two-step sampling design was performed. For the first step, GPs of the Sentinelles network were randomly selected for participation and stratified into five groups according to five regions of France: north, east, west, southwest, and southeast. For the second step, the GPs prospectively included all female patients 18 years of age and older who had presented in the last seven days with at least one of the following UTI symptoms: dysuria, frequent urination, or urgency of urination. Those patients who agreed to participate and had not taken an antibiotic in the last seven days were included. A urine sample was collected from all participants, and urine culture performed on all samples at the same laboratory. The GPs were blinded to the urine culture results.

For each included patient, the GP administered a questionnaire that was completed during the consultation. It included questions regarding the patient's demographic characteristics (age, household members, and nationality), clinical status (chronic diseases and comorbidities, particularly pregnancy, urinary tract disorder, previous UTIs, and urinary catheterization), history of pharmacological treatments before consultation (especially antibiotic use by the patient or a member of the patient's household), previous hospitalization, contact with a professional or personal healthcare worker by the patient or a member of the patient's household, international travel, contact with an animal (with information on possible antibiotic treatments administered to this animal) and the consumption of raw meat. To recover any missing data, a trained investigator telephoned the GP and the patient to verify the information within two weeks of inclusion.

According to French recommendations, complicated UTI was defined as UTI occurring in a woman with urinary tract anomalies, pregnant, aged 65 years and older or treated for a chronic disease (diabetes, cancer, renal insufficiency). To define countries at high risk of drug resistance, a wide definition was chosen based on previous publications $(2,15$, 16); if a country was located in Central/South America, Eastern/Southern Europe, Africa or Asia, it was considered to be high risk.

\section{$\underline{\text { Sample size }}$}

The sample size of the Druti study was calculated for the objective of incidence. A total of $280 \mathrm{E}$. coli-positive samples was calculated to estimate the incidence rate of UTIs caused by fluoroquinolone-resistant $E$. coli, according to an 
expected proportion of fluoroquinolone resistance of $18 \%$ and a precision of $4.5 \%$ (6). Based on the assumption of $70 \%$ positive urine cultures for suspected UTIs and $77 \%$ positive cultures caused by $E$. coli (2), it was necessary to include 520 urine samples. Considering a median number of consultations for UTls of 16 per year per GP and a proportion of eligible patients of $34 \%$, it was necessary to recruit 96 GPs to obtain 520 included patients.

\section{Bacteriological analyses}

Urine cultures, bacterial identification and susceptibility testing were performed at the Department of Microbiology of Ambroise Paré University Hospital, Paris. Leukocyte and erythrocyte counts per $\mathrm{mm}^{3}$ of urine were acquired using $\mathrm{Kova}^{\oplus}$ slides (Greiner bio one, Courtaboeuf, France). Microscopic examination after Gram staining was carried out for each sample, and the presence of bacteria was noted. Urine cultures were performed in a semi-quantitative manner using calibrated loops for plating. Isolated colonies were obtained for identification and susceptibility testing. All samples were plated on a chromogenic medium for urine analysis (uriselect4@; Biorad, Marnes-la-Coquette, France). When Gram-positive bacteria were observed at the microscopic examination, a selective medium for Gram-positive bacteria (CAN agar $+5 \%$ sheep blood, bioMérieux, Craponne, France) was added. Media were incubated at $35^{\circ} \mathrm{C}$ for 24 hours. In the event of discordance between the microscopic examination and the culture results, media were incubated for 48 hours. Urine samples were maintained at $4^{\circ} \mathrm{C}$ for one week.

After incubation, the number of bacteria and the identity of the infecting microorganism were determined, and its antimicrobial susceptibility was tested. Identification was carried out by matrix-associated laser desorption ionization time-of-flight mass spectrometry (MALDI TOF, Bruker, Ettlingen, Germany). Antimicrobial susceptibility testing was conducted using the disk diffusion method according to the recommendations of the French Society of Microbiology and the European Committee on Antimicrobial Susceptibility Testing $(17,18)$. ESBL production was detected by the API 20E and VITEK 2 systems (bioMérieux, Marcy l'Etoile, France), the double-disc synergy test, the MicroScan ESBL plus ESBL confirmation panel (Dade Behring, Sacramento, CA), and the Etest ESBL (AB Biodisk, Piscataway, NJ) $(17,19,20)$. ESBL was identified by specific PCR and sequencing, as previously described $(20,21)$.

Isolates were considered to be resistant when tests revealed resistance or intermediate susceptibility to a particular antimicrobial agent; otherwise, they were considered to be susceptible. Multi-resistance was defined as acquired resistance to at least three of the following antimicrobial categories: penicillins, penicillins and $\beta$-lactamase inhibitors, antipseudomonas penicillins and $\beta$-lactamase inhibitors, monobactams, carbapenems, non-extended spectrum cephalosporins, extended-spectrum cephalosporins, anti-MRSA (methicillin-resistant Staphylococcus aureus) cephalosporins, cephamycins, aminoglycosides, tetracyclines, glycylcyclines, folate pathway inhibitors, fluoroquinolones, phenicols, phosphonic acids and polymyxins (antimicrobial categories were dropped if species had intrinsic resistance) (22). This definition of multi-resistance Enterobacteriaceae (MDREB) (acquired resistance to at 
least three classes of antibiotic) is the definition proposed by the ECDC; it responds to a need for standardization at an international level, even if it does not take into account specific antibiotics used preferentially to treat UTIs. It does not overlap with the commonly accepted definition of multi-resistant bacteria, such as MRSA or ESBLE.

\section{$\underline{\text { Statistical analyses }}$}

The study sampling plan and design variables (stratum and weighting variables) were taken into account during analyses to permit inference of the findings to the general population (23). Stratified and sampling steps were used to accurately estimate the associated variances. For the first step, all GPs participating in the study in each geographical area were considered to be a random sample of all GPs in that region; thus, the probability of inclusion at the first stage for each geographical stratum was identical for each GP and was equal to the participation rate of the GPs in the survey. For the second step, the GPs prospectively enrolled women with a suspected UTI. Of these eligible women, only those who agreed to participate, had not taken an antibiotic in the last seven days and were able to provide a urine sample were included. Thus, the probability of inclusion at this stage was calculated for each woman according to the number of women with a urine culture result divided by the number of eligible women consulted for a UTI. Finally, estimates were post-stratified using the number of consultations for all GPs in France, according to the national health insurance system (CNAM).

For descriptive analysis, we expressed the estimated proportions of the qualitative variables with $95 \%$ confidence intervals (Cls) and the estimated mean with standard error of the quantitative variables in the population. The main outcome variable was UTI due to MDREB, as explained by the associated factors using univariate or multivariate logistic regression models and taking into account the sampling design. Those analyses were also performed for UTIs due to Enterobacteriaceae resistance only to penicillins or folate pathway inhibitors (trimethoprim-sulfamethoxazole). Variable selection was conducted as follows. First, all variables collected were assessed by univariate analysis, and those achieving a $p$-value of $<0.20$ (using the Wald test for logistic regression) were included in multivariate analysis. A backward stepwise variable selection procedure was then used to remove factors with a $p$-value of $>0.05$. Adjusted odds ratios (ORs) and $95 \% \mathrm{Cls}$ were calculated for the determinants that remained in the final model. Missing values were indicated and were excluded from the models. Data were collected with EPI-Data and analysed with R 2.10.1 statistical package, particularly the survey package (24).

\section{Ethical considerations}


The study obtained research authorization from the French independent administrative authority protecting privacy and personal data (CNIL), number 911485 (CCTIRS number 11.474), and from the local human investigation committee of lle de France $V$. 
Of the 96 expected GPs, 87 participated in the study. During the study period, 1,569 women presented to their GP with symptoms of a UTI. Figure 1 shows the flow chart of the study. Urine samples were collected from 538 of the eligible women. The three main reasons for non-inclusion were unavailability for the transport of the urine sample (34\%), lack of time of the GP for inclusion (18\%), and previous antibiotic treatment in the last 7 days (14\%). A total of 393 urine cultures were positive (74\%): 366 urine samples (93\%) had only one species of bacteria, and 26 samples (7\%) had two or three species. Majority of bacteria were Enterobacteriaceae (87\%), especially E. coli $(79 \%)$. In summary, 363 urine cultures tested positive for Enterobacteriaceae, thus, a total of 363 women were included to permit analyses.

The median age of the 363 women with Enterobacteriaceae-positive urine cultures was 45 years old. Dysuria was reported in $95 \%$ of cases, frequent urination in $92 \%$, urgency of urination in $80 \%$, pelvic pain in $40 \%$, fever in $6 \%$, and vaginal itching in $5 \%$ of cases. There was no significant difference between the clinical characteristics (dysuria, frequent urination, urgency associated with urination, pelvic pain, fever, vaginal itching) of the women with a urine culture that tested positive for MDREB and those with a culture that was positive for non-MDREB.

The following bacterial species were identified: E. coli (329 samples), Proteus mirabilis (16), Klebsiella pneumoniae (6), Citrobacter koseri (5), Klebsiella oxytoca (4), Enterobacter aerogenes (1), Enterobacter cloacae (1) and Raoultella planticola (1). Among the isolates, 68 (19\%) were MR. Estimated resistance rates for each antibiotic are listed in Table 1. No differences in the distribution of resistance between the five regions had been shown (for instance, the $p$ value for MDREB distribution across regions was 0.36 ).

Univariate analysis revealed that the following factors were associated with MDREB UTIs: antibiotic treatment taken by a household member in the previous three months $(\mathrm{OR}=2.4 ; 95 \% \mathrm{Cls}$ [1.1-5.2]); contact with animals that had taken an antibiotic in the previous three months $(\mathrm{OR}=2.9 ;[1.0-8.1])$; having provided accommodation to a resident from a country at high risk of drug resistance in the previous 12 months $(O R=5.0$; $[1.3-19.0])$; and the consumption of raw meat in the previous three months $(\mathrm{OR}=0.3 ;[0.1-0.9])$ (Table 2). Prior antibiotic use was higher among women with a urine culture that tested positive for MDREB, although this increase was not statistically significant.

The results of multivariate analysis are reported in Table 3. Significant factors identified in the final model included penicillin use by the patient in the previous three months (OR $=3.1 ;[1.2-8.0])$; having provided accommodation for a resident from a country at high risk of drug resistance in the previous twelve months $(O R=4.0 ;[1.2-15.1])$; and the consumption of raw meat in the previous three months $(\mathrm{OR}=0.3 ;[0.1-0.9])$.

Regarding monoresistance, either in univariate or multivariate analyses, only a complicated UTI was associated with resistance to penicillin, while a history of UTIs in the last 12 months was associated with trimethoprimsulfamethoxazole resistance (Tables 4 and 5). 
Among the 538 included women, only six had a UTI due to ESBLE (Table 1). Due to the small number, subgroup analyses were precluded. However, all women with a UTI due to ESBLE presented at least one of the factors identified above, including international travel in the previous twelve months $(n=3)$ and/or antibiotic treatment in the previous three months $(n=4)$. 
Among women visiting a GP in a general population setting for a UTI, the factors associated with MDREB infection are related to previous antibiotic use and exposure to a person returning from an area with a high risk of drug resistance. Furthermore, raw meat consumption could have a potentially protective role.

The rate of third-generation cephalosporin susceptibility reported in our study (98\%) was in line with the rates observed in other studies that had been published since the end of the present study, i.e., from 96 to $99 \%(25,26)$. For fluoroquinolone, we also observed a susceptibility rate of $98 \%$, while the latest published studies in France reported rates of $89 \%$ to $97 \%(25,26)$. In the study with the lowest susceptibility rate estimates, data had been transmitted by a laboratory network based on urine collected mostly for complicated UTIs, thus resulting in higher resistance rates than observed in the general population. ESBLE represented $1.6 \%$ of our sample, which is within the range of the most recently published studies, i.e., 0 to $3 \%$ of UTIs $(25,26)$. Thus, our resistance rates were comparable to the rates observed in other recent French studies. In other European countries, the resistance rates of fluoroquinolone ranged from 0.5 to $7.6 \%$, also in line with our data (27). In parallel, the total outpatient quinolone use in France in 2009 was estimated to be 2.0 defined daily dose of quinolones per 1000 habitants per day, while it ranged from 0.48 to 4.13 in other European countries (28).

The strength of the association between drug-resistant infection and antibiotic use by the patient in the present study was almost equal to that found for the risk of ampicillin-resistant $E$. coli infection in a study performed on a UK community $(O R=3.91)(29)$. However, other studies reported higher odds ratios of 18.6 for previous fluoroquinolone use and fluoroquinolone resistance in febrile E. coli UTIs (30), and 23.7 for previous antibiotic use and ESBLE infection (31). In these previous studies, patients were recruited from healthcare facilities, where a higher prevalence of antibiotic exposure and drug resistance are usually observed, possibly accounting for the differences in the magnitude of the observed risk estimates (29-32).

Previous hospitalization and urinary catheterization were not found to be associated with MDREB UTIs in this study. In a previous study of an outpatient population treated in primary healthcare centres and emergency departments for febrile E. coli UTI, these factors have been associated with fluoroquinolone resistance $(\mathrm{OR}=2.28$ for previous hospitalization and $\mathrm{OR}=6.02$ for urinary catheterization) (30). Again, the lower rates reported in our study may be due to our evaluation of the general population versus the hospital-based populations that have been assessed in previous studies. 
other studies reporting that raw chicken consumption increases the risk of antibiotic-resistant infection (33). However, a recent study has found this same "protective" association between raw meat consumption and CTX-M-producing E. coli (34). The authors have suggested that raw meat consumption is linked to nationality and that its consumption may have been more prevalent in the native population than in the foreign population studied, which may have a higher rate of antibiotic resistance. However, in the present study, raw meat consumption was not found to be linked to nationality or occupational grade (data not shown). Thus, further studies are needed to determine whether this association between raw meat consumption and antimicrobial-resistant UTIs is mainly an artefact or is due to a direct protective impact on commensal flora, to a bias related to nationality (raw meat consumption is rather unusual in many countries), or to other socio-professional characteristics.

Several studies have identified an association of geographical factors, including nationality and international travel, with antibiotic-resistant UTIs $(9-11,34)$. In this study, we did not detect these associations. However, contact with a resident from a country with a high risk of drug resistance was strongly associated with MDREB UTIs, suggesting the cross-transmission of resistant bacteria.

This study had a few limitations. There were lower rates of resistance than expected, particularly for fluoroquinolone, resulting in a lack of statistical power. This possibly explains why we did not confirm other previously identified risk factors for resistant UTIs, such as previous UTI, nationality, travel, previous hospitalization, or urinary catheterization (9-11, 34). For antibiotics with a high rate of resistance (penicillin or trimethoprim-sulfamethoxazole), association with previously identified risk factors was not evidenced in our community study. As carriage of antibiotic resistance of $E$. coli in faecal flora is important, nearly $20 \%$ for ampicillin or trimethoprim-sulfamethoxazole $(13,35)$, it might be hypothesized that individual factors play only an accessory role in resistance acquisition. This acquisition would be more passive than active, resulting from "living there" more than "doing this".

Although the design of our study had the above-mentioned limitations, it allowed for more precise evaluations of the weights of different factors for antibiotic-resistant UTIS in the general population. This study is one of the first to systematically collect urine samples from all women in a population presenting with symptoms of a UTI in general practice. Microbial data on UTIs are typically based on urine samples associated with healthcare-related UTI cases. Our findings expand upon the available data based on healthcare-related populations $(34,36)$. The sampling design and post-stratification corrected biases stem from subject dropout and geographical repartition. Lastly, another strength of this study was in the standardized collection of data, which limited information bias. 
The authors declare that they have no competing interests.

\section{Authors' contributions}

LR, SM, SV, TB, BC and TH conceived and designed the experiments. LR, SM and BH performed the experiments. LR, AB and YLS analysed the data. LR, SM, SV, SK, AB, YLS, BH, TB, BC and TH wrote the paper.

\section{Acknowledgements}

We thank all of the GPs and their patients. The authors received grants from the Health General Direction of France (DGS), the Corporate Foundation GPM, and the French Urology Association during the study period. The funders had no role in the study design, data collection, analyses, decision to publish or preparation of the manuscript. 
Figures

Figure 1 - Flow chart 
Table 1: Resistance rates* for Enterobacteriaceae in urinary tract infections, France, 2012/2013.

Percentages [95\% confidence intervals] **

Amoxicillin

Amoxicillin-clavulanic acid

C3G (cefotaxim, ceftazidime)

Nalidixic acid

Ofloxacin

Ciprofloxacin

Trimethoprim-sulfamethoxazole

Nitrofurantoin

Fosfomycin

ESBLE

At least one antibiotic

Antibiotic multi-resistant ${ }^{m * *}$

\section{1 [36-46]}

9 [6-12]

$2[1-4]$

5 [3-8]

5 [3-7]

$2[1-4]$

18 [13-24]

$6[3-10]$

0

$1[1-4]$

49 [43-54]

19 [15-26]

* Enterobacteriaceae were classified as being resistant when testing revealed resistance or intermediate susceptibility to a particular antimicrobial agent;

** Proportions were estimated according to the sampling design;

*** Acquired resistance to at least three classes of antibiotics (22);

ESBLE: extended-spectrum $\beta$-lactamase Enterobacteriaceae;

C3G: third-generation cephalosporin. 
Table 2: Factors associated with antibiotic-multi-resistant Enterobacteriaceae (MDREB) urinary tract infections (UTIs): univariate analysis performed according to the sampling design

\begin{tabular}{|c|c|c|c|c|c|}
\hline & $\begin{array}{l}\text { MDREB } \\
\text { N=68, } \\
\text { (sample } \\
\text { size, \%**) }\end{array}$ & $\begin{array}{l}\text { Non- } \\
\text { MDREB } \\
\text { N=295, } \\
\text { (sample } \\
\text { size, \%**) }\end{array}$ & OR $[95 \% \mathrm{Cl}]$ & $p$ value ${ }^{*}$ & $\begin{array}{l}\text { Missing } \\
\text { value }\end{array}$ \\
\hline UTI in the last 12 months & $58(86)$ & $242(82)$ & $1.3[0.5-3.6]$ & 0.58 & 1 \\
\hline Complicated UTI $^{\pi \times x}$ & $3(2)$ & $27(8)$ & $0.3[0.1-1.0]$ & 0.06 & 2 \\
\hline Patients with $\geq$ four UTIs/year & $5(7)$ & $23(7)$ & $1.1[0.4-2.7]$ & 0.91 & 1 \\
\hline Antibiotic use by the patient in the previous three months & $20(29)$ & $55(20)$ & $1.6[0.6-4.1]$ & 0.35 & 1 \\
\hline Penicillin in the previous three months & $9(18)$ & $20(7)$ & $2.8[1.0-8.0]$ & 0.06 & 1 \\
\hline Quinolone in the previous three months & $5(5)$ & $13(5)$ & 0.9 [0.3-3.3] & 0.89 & 1 \\
\hline Other antibiotics in the previous three months & $7(7)$ & $23(6)$ & $1.2[0.5-3.0]$ & 0.72 & 1 \\
\hline $\begin{array}{l}\text { Antibiotic use by a household member in the previous } \\
\text { three months }\end{array}$ & $17(27)$ & $39(13)$ & $2.4[1.1-5.2]$ & 0.03 & 1 \\
\hline Hospitalization in the previous 12 months & $5(6)$ & $36(14)$ & $0.4[0.2-1.1]$ & 0.07 & 2 \\
\hline Healthcare contact in the previous month & $16(17)$ & $66(21)$ & $0.8[0.4-1.6]$ & 0.52 & 1 \\
\hline Household healthcare contact in the previous month & $16(20)$ & $46(14)$ & $1.6[0.7-3.8]$ & 0.31 & 1 \\
\hline International travel in the previous 12 months & $19(23)$ & $72(27)$ & $0.8[0.4-1.5]$ & 0.50 & 1 \\
\hline $\begin{array}{l}\text { International travel in the previous twelve months } \\
\text { in countries at high risk of drug resistance }\end{array}$ & $13(15)$ & $59(24)$ & $0.6[0.3-1.1]$ & 0.08 & 4 \\
\hline $\begin{array}{l}\text { Providing accommodation for a resident from a country at } \\
\text { high risk of drug resistance in the previous twelve months }\end{array}$ & $5(9)$ & $7(2)$ & $5.0[1.3-19.0]$ & 0.03 & 1 \\
\hline Daily contact with animal & $38(56)$ & $154(49)$ & $1.3[0.7-2.4]$ & 0.40 & 1 \\
\hline $\begin{array}{l}\text { Contact with animals having taken antibiotics in } \\
\text { the previous three months }\end{array}$ & $7(13)$ & $17(5)$ & $2.9[1.0-8.1]$ & 0.05 & 3 \\
\hline Living alone & $13(17)$ & $50(18)$ & $1.0[0.4-2.4]$ & 0.94 & 1 \\
\hline Foreign nationality & $1(1)$ & $13(4)$ & $0.2[0.03-2.0]$ & 0.19 & 1 \\
\hline Age $\geq 65$ years old & $15(18)$ & $50(15)$ & $1.3[0.6-3.1]$ & 0.51 & 0 \\
\hline Consumption of raw meat in the previous three months & $5(6)$ & $46(19)$ & $0.3[0.1-0.9]$ & 0.03 & 2 \\
\hline
\end{tabular}

*Wald test; OR: odds ratio; MDR: antibiotic multi-resistant; ** proportions were estimated with the sampling design, which explain why it is not equal to numerator / denominator; ${ }^{* * *}$ occurring in women with urinary tract anomalies, pregnancy, those over 65 years old, or those with a chronic disease (diabetes, recent or recurring cancer, or renal insufficiency) 


\section{ACCEPTED MANUSCRIPT}

Table 3: Factors associated with antibiotic-multi-resistant Enterobacteriaceae urinary tract infections: multivariate analysis performed according to the sampling design

OR $[95 \% \mathrm{Cls}] \quad$ p value

Penicillin use by the patient in the previous three months

$3.1[1.2-8.0] \quad 0.02$

Providing accommodation for a resident from a country at high risk of drug $4.0[1.2-15.1]$

0.03

resistance in the previous 12 months

Consumption of raw meat in the previous three months

$0.3[0.1-0.9]$

0.04

*Wald test; OR: odds ratio; and Cls: confidence intervals. Two observations were deleted due to missing values. 


\begin{tabular}{|c|c|c|c|c|c|}
\hline & $\begin{array}{l}\text { PN EB } \\
N=139, \\
\text { sample size } \\
\left(\%^{* *}\right)\end{array}$ & $\begin{array}{l}\text { Not PN EB } \\
N=224 \text {, sample } \\
\text { size }(\% * *)\end{array}$ & OR $[95 \% \mathrm{Cl}]$ & $p$ value* & $\begin{array}{l}\text { Missing } \\
\text { value }\end{array}$ \\
\hline UTI in the last twelve months & $117(84)$ & $183(81)$ & $1.5[0.7-3.0]$ & 0.28 & 1 \\
\hline Complicated UTI $^{\pi \times \pi}$ & $10(4)$ & $20(9)$ & $0.4[0.2-0.9]$ & 0.04 & 2 \\
\hline Patients with $\geq$ four UTIs/year & $13(10)$ & $15(4)$ & $2.5[0.9-6.4]$ & 0.06 & 1 \\
\hline $\begin{array}{l}\text { Antibiotic use by the patient in the previous } \\
\text { three months }\end{array}$ & $37(28)$ & $38(18)$ & $1.8[0.8-3.8]$ & 0.15 & 1 \\
\hline Penicillin in the previous three months & $14(12)$ & $15(8)$ & $1.6[0.4-6.1]$ & 0.47 & 1 \\
\hline $\begin{array}{l}\text { Quinolone in the previous three } \\
\text { months }\end{array}$ & $9(7)$ & $9(4)$ & $1.6[0.5-5.3]$ & 0.44 & 1 \\
\hline $\begin{array}{l}\text { Other antibiotics in the previous three } \\
\text { months }\end{array}$ & $14(7)$ & $16(6)$ & $1.2[0.5-2.9]$ & 0.65 & 1 \\
\hline $\begin{array}{l}\text { Antibiotic use by a household member in the } \\
\text { previous three months }\end{array}$ & $27(20)$ & $29(13)$ & $1.8[0.9-3.4]$ & 0.10 & 1 \\
\hline Hospitalization in the previous 12 months & $12(9)$ & $29(14)$ & $0.6[0.2-1.4]$ & 0.21 & 2 \\
\hline Healthcare contact in the previous month & $28(16)$ & $54(23)$ & $0.7[0.4-1.2]$ & 0.20 & 1 \\
\hline $\begin{array}{l}\text { Household healthcare contact in the previous } \\
\text { month }\end{array}$ & $24(16)$ & $38(14)$ & $1.1[0.6-2.0]$ & 0.63 & 1 \\
\hline International travel in the previous 12 months & $36(28)$ & $55(25)$ & $1.2[0.7-2.0]$ & 0.56 & 1 \\
\hline $\begin{array}{l}\text { International travel in the previous } \\
\text { twelve months in countries at high risk } \\
\text { of drug resistance }\end{array}$ & $25(21)$ & $47(23)$ & $0.9[0.5-1.6]$ & 0.68 & 4 \\
\hline $\begin{array}{l}\text { Providing accommodation for a resident from a } \\
\text { country at high risk of drug resistance in the } \\
\text { previous twelve months }\end{array}$ & $6(5)$ & $6(2)$ & $2.2[0.6-8.3]$ & 0.25 & 1 \\
\hline Daily contact with animal & $71(51)$ & $121(50)$ & $1.0[0.6-1.9]$ & 0.89 & 1 \\
\hline $\begin{array}{l}\text { Contact with animals having taken } \\
\text { antibiotics in the previous three months }\end{array}$ & $10(8)$ & $14(6)$ & $1.4[0.5-3.8]$ & 0.52 & 3 \\
\hline Living alone & $29(19)$ & $34(17)$ & $1.1[0.4-2.8]$ & 0.88 & 1 \\
\hline Foreign nationality & $5(4)$ & $9(3)$ & $1.6[0.4-7.1]$ & 0.53 & 1 \\
\hline Age $\geq 65$ years old & $25(14)$ & $40(16)$ & $0.8[0.4-1.5]$ & 0.51 & 0 \\
\hline $\begin{array}{l}\text { Consumption of raw meat in the previous three } \\
\text { months }\end{array}$ & $18(19)$ & $33(15)$ & $1.3[0.6-2.5]$ & 0.51 & 2 \\
\hline
\end{tabular}

*Wald test; OR: odds ratio; ${ }^{* *}$ proportions were estimated with the sampling design, which explain why it is not equal to numerator / denominator; ; ${ }^{* *}$ occurring in women with urinary tract anomalies, pregnancy, those over 65 years old, or those with a chronic disease (diabetes, recent or recurring cancer, or renal insufficiency 
Table 5: Factors associated with trimethoprim-sulfamethoxazole-resistant (TMP) Enterobacteriaceae (EB) urinary tract infections (UTIs): univariate analysis with the sampling design

\begin{tabular}{|c|c|c|c|c|c|}
\hline & $\begin{array}{l}\text { TMP EB } \\
\mathrm{N}=58 \text {, sample } \\
\text { size }(\% \text { \%*) }\end{array}$ & $\begin{array}{l}\text { Not TMP EB } \\
N=305 \text {, sample } \\
\text { size }(\% * *)\end{array}$ & OR $[95 \% \mathrm{Cl}]$ & $p$ value* & $\begin{array}{l}\text { Missing } \\
\text { value }\end{array}$ \\
\hline UTI in the last twelve months & $52(93)$ & $248(80)$ & $3.4[1.3-8.8]$ & 0.02 & 1 \\
\hline Complicated UTI $^{\pi \times}$ & $4(3)$ & $26(8)$ & $0.4[0.1-1.3]$ & 0.13 & 2 \\
\hline Patients with $\geq$ four UTIs/year & $6(9)$ & $22(6)$ & $1.4[0.5-3.5]$ & 0.51 & 1 \\
\hline $\begin{array}{l}\text { Antibiotic use by the patient in the previous } \\
\text { three months }\end{array}$ & $17(31)$ & $58(20)$ & $1.8[0.9-3.8]$ & 0.11 & 1 \\
\hline Penicillin in the previous three months & $6(16)$ & $23(8)$ & $2.2[0.7-6.8]$ & 0.17 & 1 \\
\hline $\begin{array}{l}\text { Quinolone in the previous three } \\
\text { months }\end{array}$ & $4(5)$ & $14(5)$ & 0.9 [0.3-3.1] & 0.87 & 1 \\
\hline $\begin{array}{l}\text { Other antibiotics in the previous three } \\
\text { months }\end{array}$ & $6(8)$ & $24(6)$ & $1.3[0.4-4.1]$ & 0.62 & 1 \\
\hline $\begin{array}{l}\text { Antibiotic use by a household member in the } \\
\text { previous three months }\end{array}$ & $10(17)$ & $46(16)$ & $1.1[0.5-2.6]$ & 0.84 & 1 \\
\hline Hospitalization in the previous 12 months & $4(6)$ & $37(13)$ & $0.4[0.1-1.3]$ & 0.13 & 2 \\
\hline Healthcare contact in the previous month & $10(19)$ & $72(20)$ & $0.9[0.4-2.1]$ & 0.81 & 1 \\
\hline $\begin{array}{l}\text { Household healthcare contact in the previous } \\
\text { month }\end{array}$ & $10(11)$ & $52(16)$ & $0.6[0.3-2.1]$ & 0.24 & 1 \\
\hline International travel in the previous 12 months & $18(37)$ & $73(24)$ & $1.8[0.8-4.0]$ & 0.15 & 1 \\
\hline $\begin{array}{l}\text { International travel in the previous } \\
\text { twelve months in countries at high risk } \\
\text { of drug resistance }\end{array}$ & $12(27)$ & $60(21)$ & $1.4[0.5-3.6]$ & 0.49 & 4 \\
\hline $\begin{array}{l}\text { Providing accommodation for a resident from a } \\
\text { country at high risk of drug resistance in the } \\
\text { previous twelve months }\end{array}$ & $3(6)$ & $9(3)$ & $2.7[0.6-1.1]$ & 0.19 & 1 \\
\hline Daily contact with animal & $30(58)$ & $162(49)$ & $1.4[0.7-2.8]$ & 0.30 & 1 \\
\hline $\begin{array}{l}\text { Contact with animals having taken } \\
\text { antibiotics in the previous three months }\end{array}$ & $4(7)$ & $20(6)$ & $1.2[0.3-4.3]$ & 0.76 & 3 \\
\hline Living alone & $14(23)$ & $49(17)$ & $1.5[0.8-3.1]$ & 0.24 & 1 \\
\hline Foreign nationality & $1(1)$ & $13(4)$ & $0.3[0.03-2.2]$ & 0.22 & 1 \\
\hline Age $\geq 65$ years old & $13(20)$ & $52(14)$ & $1.5[0.7-2.9]$ & 0.30 & 0 \\
\hline $\begin{array}{l}\text { Consumption of raw meat in the previous three } \\
\text { months }\end{array}$ & 9 (24) & $42(14)$ & $1.8[0.7-1.8]$ & 0.22 & 2 \\
\hline
\end{tabular}

*Wald test; OR: odds ratio; ${ }^{*}$ proportions were estimated with the sampling design, which explain why it is not equal to numerator / denominator; ${ }^{* *}$ occurring in women with urinary tract anomalies, pregnancy, those over 65 years old, or those with a chronic disease (diabetes, recent or recurring cancer, or renal insufficiency 
1. Foxman B, Barlow R, D'Arcy H, Gillespie B, Sobel JD. Urinary tract infection: self-reported incidence and associated costs. Ann Epidemiol. 2000 Nov;10(8):509-15. PubMed PMID: 11118930. Epub 2000/12/19. eng.

2. Naber KG, Schito G, Botto H, Palou J, Mazzei T. Surveillance study in Europe and Brazil on clinical aspects and Antimicrobial Resistance Epidemiology in Females with Cystitis (ARESC): implications for empiric therapy. European urology. 2008 Nov;54(5):1164-75. PubMed PMID: 18511178. Epub 2008/05/31. eng.

3. Le TP, Miller LG. Empirical therapy for uncomplicated urinary tract infections in an era of increasing antimicrobial resistance: a decision and cost analysis. Clin Infect Dis. 2001 Sep 1;33(5):615-21. PubMed PMID: 11486284. Epub 2001/08/07. eng.

4. Goossens H, Ferech M, Vander Stichele R, Elseviers M. Outpatient antibiotic use in Europe and association with resistance: a cross-national database study. Lancet. 2005 Feb 12-18;365(9459):579-87. PubMed PMID: 15708101. Epub 2005/02/15. eng.

5. Costelloe C, Metcalfe C, Lovering A, Mant D, Hay AD. Effect of antibiotic prescribing in primary care on antimicrobial resistance in individual patients: systematic review and meta-analysis. BMJ. 2010;340:c2096. PubMed PMID: 20483949. Epub 2010/05/21. eng.

6. ECDC. Antimicrobial resistance surveillance in Europe 2009. Annual report of the European Antimicrobial Resistance Surveillance Network (EARS-Net). Stockholm: ECDC; 2010. Available from: http://www.ecdc.europa.eu/en/publications/Publications/1011 SUR annual EARS Net 2009.pdf.

7. Carbonne A, Arnaud I, Maugat S, Marty N, Dumartin C, Bertrand X, et al. National multidrug-resistant bacteria (MDRB) surveillance in France through the RAISIN network: a 9 year experience. The Journal of antimicrobial chemotherapy. 2013 Apr;68(4):954-9. PubMed PMID: 23194721.

8. Hooton TM, Besser R, Foxman B, Fritsche TR, Nicolle LE. Acute uncomplicated cystitis in an era of increasing antibiotic resistance: a proposed approach to empirical therapy. Clin Infect Dis. 2004 Jul 1;39(1):75-80. PubMed PMID: 15206056. Epub 2004/06/19. eng.

9. Arslan H, Azap OK, Ergonul O, Timurkaynak F. Risk factors for ciprofloxacin resistance among Escherichia coli strains isolated from community-acquired urinary tract infections in Turkey. The Journal of antimicrobial chemotherapy. 2005 Nov;56(5):914-8. PubMed PMID: 16174685. Epub 2005/09/22. eng.

10. Colodner R, Kometiani I, Chazan B, Raz R. Risk factors for community-acquired urinary tract infection due to quinolone-resistant E. coli. Infection. 2008 Feb;36(1):41-5. PubMed PMID: 18193386. Epub 2008/01/15. eng.

11. Colgan R, Johnson JR, Kuskowski M, Gupta K. Risk factors for trimethoprim-sulfamethoxazole resistance in patients with acute uncomplicated cystitis. Antimicrobial agents and chemotherapy. 2008 Mar;52(3):846-51. PubMed PMID: 18086847. Pubmed Central PMCID: 2258492. Epub 2007/12/19. eng.

12. Soraas A, Sundsfjord A, Sandven I, Brunborg C, Jenum PA. Risk factors for community-acquired urinary tract infections caused by ESBL-producing enterobacteriaceae--a case-control study in a low prevalence country. PloS one. 2013;8(7):e69581. PubMed PMID: 23936052. Pubmed Central PMCID: 3720588. Epub 2013/08/13. eng.

13. Nicolas-Chanoine MH, Gruson C, Bialek-Davenet S, Bertrand X, Thomas-Jean F, Bert F, et al. 10-Fold increase (2006-11) in the rate of healthy subjects with extended-spectrum beta-lactamase-producing Escherichia coli faecal carriage in a Parisian check-up centre. The Journal of antimicrobial chemotherapy. 2013 Mar;68(3):562-8. PubMed PMID: 23143897. Epub 2012/11/13. eng.

14. Flahault A, Blanchon T, Dorleans Y, Toubiana L, Vibert JF, Valleron AJ. Virtual surveillance of communicable diseases: a 20-year experience in France. Stat Methods Med Res. 2006 Oct;15(5):413-21. PubMed PMID: 17089946. Epub 2006/11/09. eng.

15. Kahlmeter G. An international survey of the antimicrobial susceptibility of pathogens from uncomplicated urinary tract infections: the ECO.SENS Project. The Journal of antimicrobial chemotherapy. 2003 Jan;51(1):69-76. PubMed PMID: 12493789. Epub 2002/12/21. eng.

16. Vodovar D, Marcade G, Raskine L, Malissin I, Megarbane B. [Enterobacteriaceae producing extended spectrum beta-lactamase: epidemiology, risk factors, and prevention]. Rev Med Interne. 2013 Nov;34(11):687-93. PubMed PMID: 23182290. Enterobacteries productrices de beta-lactamases a spectre elargi : epidemiologie, facteurs de risque et mesures de prevention.

17. Société française de microbiologie. Recommandations du comité de l'antibiogramme de la société française de microbiologie 2013. Available from: http://www.sfm-microbiologie.org. 
18. European Commitee on Antimicrobial Susceptibility Testing. Breakpoint Tables for Interpretation of MICs and Zone Diameters, Versions 1.3 and 2.0

2013 [11 December 2014]. Available from:

http://www.eucast.org/antimicrobial susceptibility testing/previous versions of tables/.

19. Jarlier V, Nicolas MH, Fournier G, Philippon A. Extended broad-spectrum beta-lactamases conferring transferable resistance to newer beta-lactam agents in Enterobacteriaceae: hospital prevalence and susceptibility patterns. Rev Infect Dis. 1988 Jul-Aug;10(4):867-78. PubMed PMID: 3263690.

20. De Champs C, Chanal C, Sirot D, Baraduc R, Romaszko JP, Bonnet R, et al. Frequency and diversity of Class A extended-spectrum beta-lactamases in hospitals of the Auvergne, France: a 2 year prospective study. The Journal of antimicrobial chemotherapy. 2004 Sep;54(3):634-9. PubMed PMID: 15282240.

21. Eckert C, Gautier V, Saladin-Allard M, Hidri N, Verdet C, Ould-Hocine Z, et al. Dissemination of CTX-M-type beta-lactamases among clinical isolates of Enterobacteriaceae in Paris, France. Antimicrobial agents and chemotherapy. 2004 Apr;48(4):1249-55. PubMed PMID: 15047527. Pubmed Central PMCID: 375249.

22. Magiorakos AP, Srinivasan A, Carey RB, Carmeli Y, Falagas ME, Giske CG, et al. Multidrug-resistant, extensively drug-resistant and pandrug-resistant bacteria: an international expert proposal for interim standard definitions for acquired resistance. Clinical microbiology and infection : the official publication of the European Society of Clinical Microbiology and Infectious Diseases. 2012 Mar;18(3):268-81. PubMed PMID: 21793988. Epub 2011/07/29. eng.

23. Lemeshow S, Letenneur L, Dartigues JF, Lafont S, Orgogozo JM, Commenges D. Illustration of analysis taking into account complex survey considerations: the association between wine consumption and dementia in the PAQUID study. Personnes Ages Quid. Am J Epidemiol. 1998 Aug 1;148(3):298-306. PubMed PMID: 9690368. Epub 1998/08/05. eng.

24. Lumley T. Analysis of complex survey samples. Journal of Statistical Software. 2004;9(1):1-19.

25. ONERBA. Annual report 2011-2012: ONERBA; 2014 [cited 2014 2015/04/21]. Available from:

http://www.onerba.org/IMG/pdf/onerba rapport 2011 web.pdf.

26. Etienne M, Lefebvre E, Frebourg N, Hamel H, Pestel-Caron M, Caron F, et al. Antibiotic treatment of acute uncomplicated cystitis based on rapid urine test and local epidemiology: lessons from a primary care series. BMC infectious diseases. 2014;14(1):137. PubMed PMID: 24612927.

27. Kahlmeter G, Poulsen HO. Antimicrobial susceptibility of Escherichia coli from community-acquired urinary tract infections in Europe: the ECO.SENS study revisited. International journal of antimicrobial agents. 2012 Jan;39(1):45-51. PubMed PMID: 22055529.

28. Adriaenssens N, Coenen S, Versporten A, Muller A, Minalu G, Faes C, et al. European Surveillance of Antimicrobial Consumption (ESAC): outpatient quinolone use in Europe (1997-2009). The Journal of antimicrobial chemotherapy. 2011 Dec;66 Suppl 6:vi47-56. PubMed PMID: 22096066.

29. Hillier S, Roberts Z, Dunstan F, Butler C, Howard A, Palmer S. Prior antibiotics and risk of antibiotic-resistant community-acquired urinary tract infection: a case-control study. The Journal of antimicrobial chemotherapy. 2007 Jul;60(1):92-9. PubMed PMID: 17540675. Epub 2007/06/02. eng.

30. van der Starre WE, van Nieuwkoop C, Paltansing S, van't Wout JW, Groeneveld GH, Becker MJ, et al. Risk factors for fluoroquinolone-resistant Escherichia coli in adults with community-onset febrile urinary tract infection. The Journal of antimicrobial chemotherapy. 2011 Mar;66(3):650-6. PubMed PMID: 21123286.

31. Siedelman L, Kline S, Duval S. Risk factors for community- and health facility-acquired extended-spectrum beta-lactamase-producing bacterial infections in patients at the University of Minnesota Medical Center, Fairview. American journal of infection control. 2012 Nov;40(9):849-53. PubMed PMID: 22325481.

32. Aguilar-Duran S, Horcajada JP, Sorli L, Montero M, Salvado M, Grau S, et al. Community-onset healthcarerelated urinary tract infections: comparison with community and hospital-acquired urinary tract infections. The Journal of infection. 2012 May;64(5):478-83. PubMed PMID: 22285591.

33. Overdevest I, Willemsen I, Rijnsburger M, Eustace A, Xu L, Hawkey P, et al. Extended-spectrum betalactamase genes of Escherichia coli in chicken meat and humans, The Netherlands. Emerging infectious diseases. 2011 Jul;17(7):1216-22. PubMed PMID: 21762575. Pubmed Central PMCID: 3381403.

34. Nicolas-Chanoine MH, Jarlier V, Robert J, Arlet G, Drieux L, Leflon-Guibout V, et al. Patient's origin and lifestyle associated with CTX-M-producing Escherichia coli: a case-control-control study. PloS one. 2012;7(1):e30498. PubMed PMID: 22299043. Pubmed Central PMCID: 3267726. Epub 2012/02/03. eng. 
35. Skurnik D, Bonnet D, Bernede-Bauduin C, Michel R, Guette C, Becker JM, et al. Characteristics of human intestinal Escherichia coli with changing environments. Environmental microbiology. 2008 Aug;10(8):2132-7. PubMed PMID: 18459976.

36. Gupta K, Hooton TM, Naber KG, Wullt B, Colgan R, Miller LG, et al. International clinical practice guidelines for the treatment of acute uncomplicated cystitis and pyelonephritis in women: A 2010 update by the Infectious Diseases Society of America and the European Society for Microbiology and Infectious Diseases. Clin Infect Dis. 2011 Mar 1;52(5):e103-20. PubMed PMID: 21292654. 


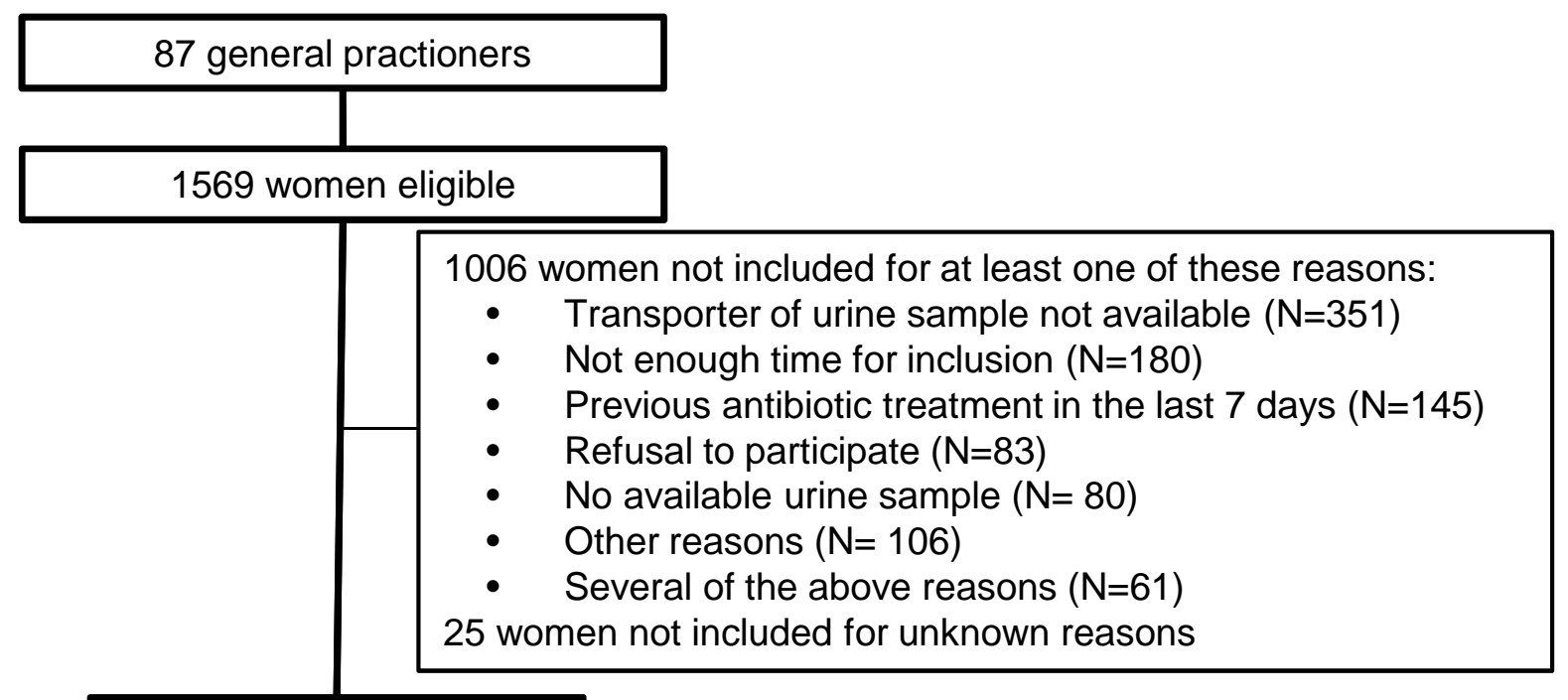

1006 women not included for at least one of these reasons:

- $\quad$ Transporter of urine sample not available $(\mathrm{N}=351)$

- $\quad$ Not enough time for inclusion $(\mathrm{N}=180)$

- $\quad$ Previous antibiotic treatment in the last 7 days $(\mathrm{N}=145)$

Refusal to participate $(\mathrm{N}=83)$

- No available urine sample $(\mathrm{N}=80)$

- $\quad$ Other reasons $(\mathrm{N}=106)$

25 women not included for unknown reasons

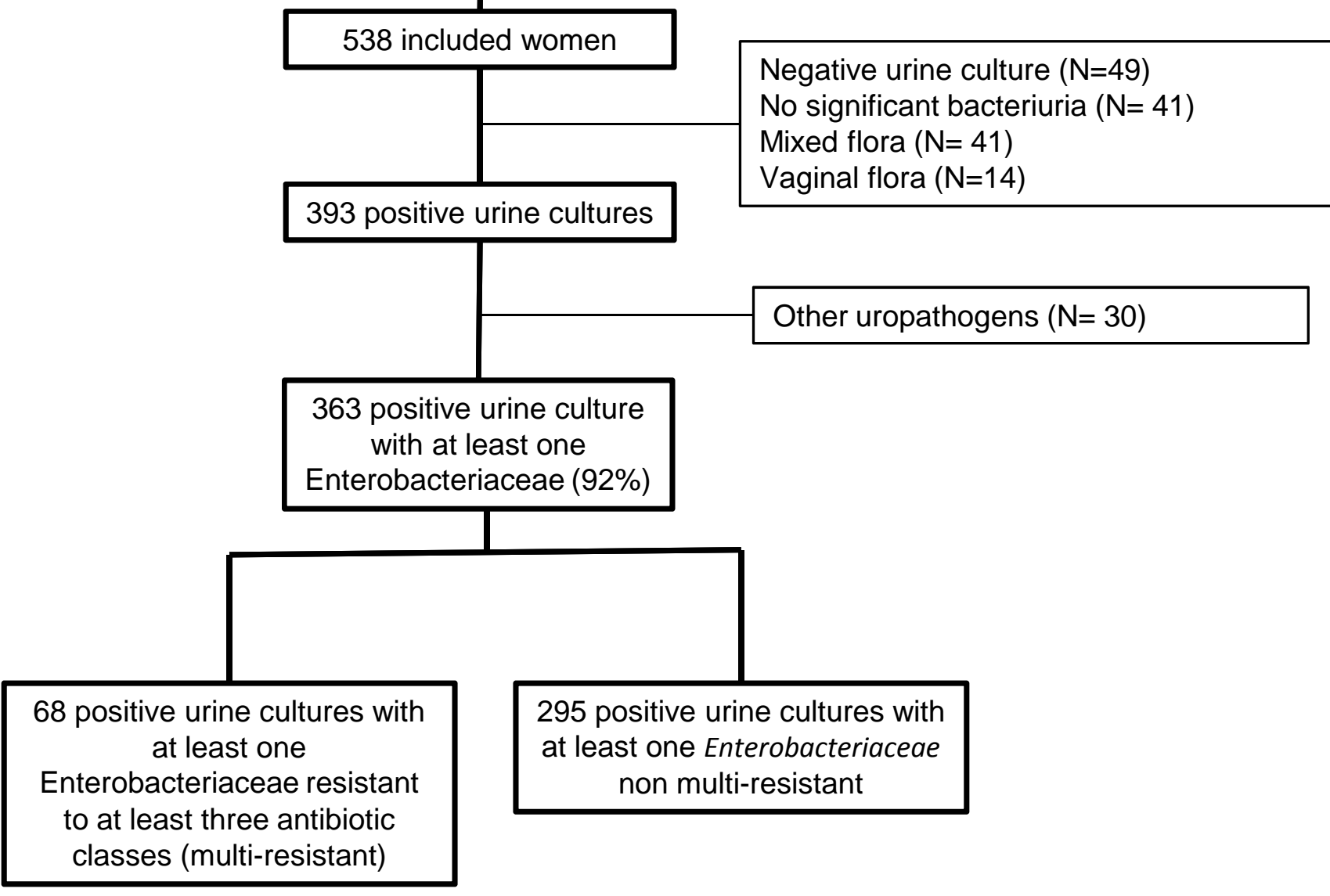

